\title{
Congenital malformations
}

\section{A clinico-pathological conference held at the Royal Alexandra Hospital for Sick Children, Brighton, on Friday, 14 January 1966}

\author{
Chairman: Trevor P. Mann \\ M.D., F.R.C.P. \\ Consultant Paediatrician to the Brighton \& Lewes \\ and Mid-Sussex Groups of Hospitals
}

Dr C. B. S. Wood: Susan E. was born in the Sussex Maternity Hospital to a 41-year-old woman who already had an unfortunate obstetric history. Her husband is about the same age as she is and she had had five pregnancies. The first two had ended in miscarriage at 3 months and her third and fourth pregnancies had resulted in premature deliveries of healthy children who are now alive and well. The smaller one was the third and the birth weight was $5 \mathrm{lb} 10 \mathrm{oz}$. The child that we are considering now had a birth weight of $6 \mathrm{lb} 1 \mathrm{oz}$ and she was born normally at 38 weeks, having mild blue asphyxia. As far as we know the pregnancy was quite normal. It is recorded in the maternity notes that they wondered if she had twins because she was rather large. There was no clinical evidence of hydramnios. After being delivered the child recovered from asphyxia quite well, but had two early cyanotic attacks and it was obvious from the beginning that this was a very abnormal child.

I would like to show you the pictures now and talk about them as I go. It will be seen that she has a most hideous hare-lip and cleft palate (Fig. 1). She also had a strikingly receding forehead, keeled in the mid-line, with a narrow parietal measurement. The head circumference was $11 \frac{3}{4}$ in. and this is well below the third percentile for a child weighing $6 \mathrm{lb} 1 \mathrm{oz}$. She had small eyes and, although it is not easy to see from this picture, she had rather primitively formed ears with primitive helixes and they are rather low set.

The eyes are rather close together; when open one could see that they were structurally normal. The marked recession in the frontal region is seen in this picture (Fig. 2) and there one can see the ears better. You will also notice a rather flat back to the head. Apart from the obvious abnormality in the face and head, the most striking finding was an exomphalos, not a large one, which was easy to reduce. Elsewhere, she had rather widely spaced nipples and long thumbs which were much more like fingers. On looking carefully at the lower limbs we found nothing very remarkable except that there seemed to be an abnormal crease between the first an

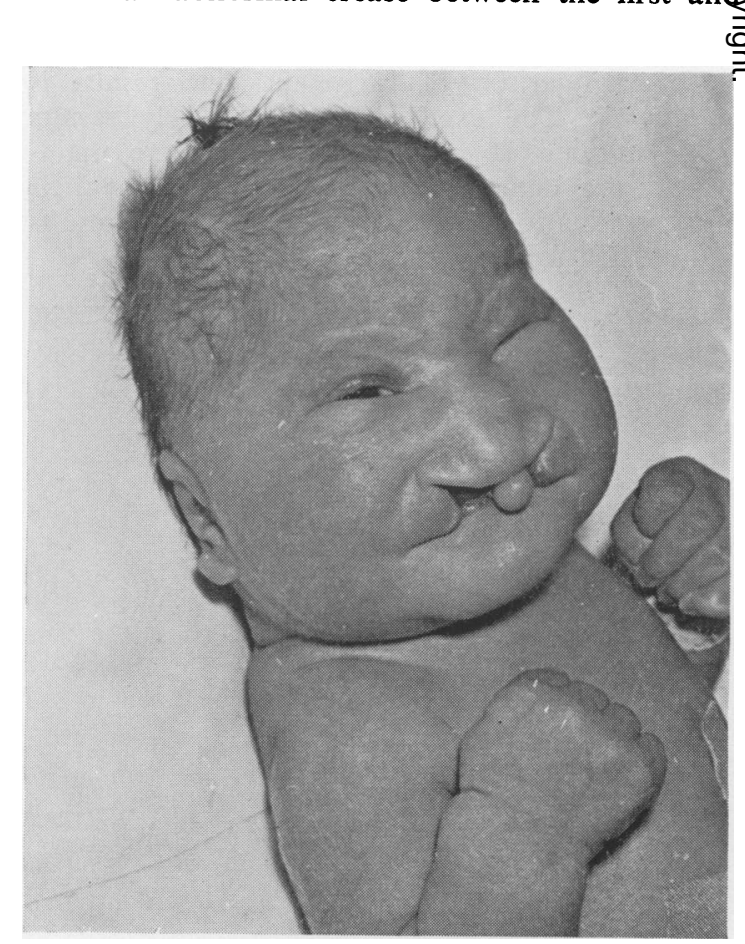

FIG. 1. Susan E. Front view of face. 
second toes. In the hands she had simian creases on both sides.

During the first few hours of life she had several profound cyanotic attacks with temporary cessation of respiration and profound bradycardia. It was only when she had these episodes that one could hear a cardiac murmur. She did very badly in hospital and recurrent cyanotic attacks occurred, one of which was finally fatal. I wonder if I could ask Dr Rubin to show us the $\mathrm{X}$-rays.

Dr J. Rubin: Only the chest and abdomen were examined during life when Susan was about 12 hours old. The essential feature was definite but not severe cardiac enlargement, probably mainly right-sided. The lungs were not congested at that time.

The necropsy $X$-ray pictures do not show the limb bones well enough, but the skull is smaller than average for the age and there are circular areas of diminished bone density suggesting poor mineralization.

Dr P. A. Trorr: At necropsy, apart from the changes which Dr Wood has already described, $I$ found a curious $V$-shaped marking posteriorly over the sacrum which consisted of two "pin pricks' about $2 \mathrm{~cm}$ apart from which there arose two lines which passed downwards and medially to meet in the mid-line to form a ' $\mathrm{V}$ '.

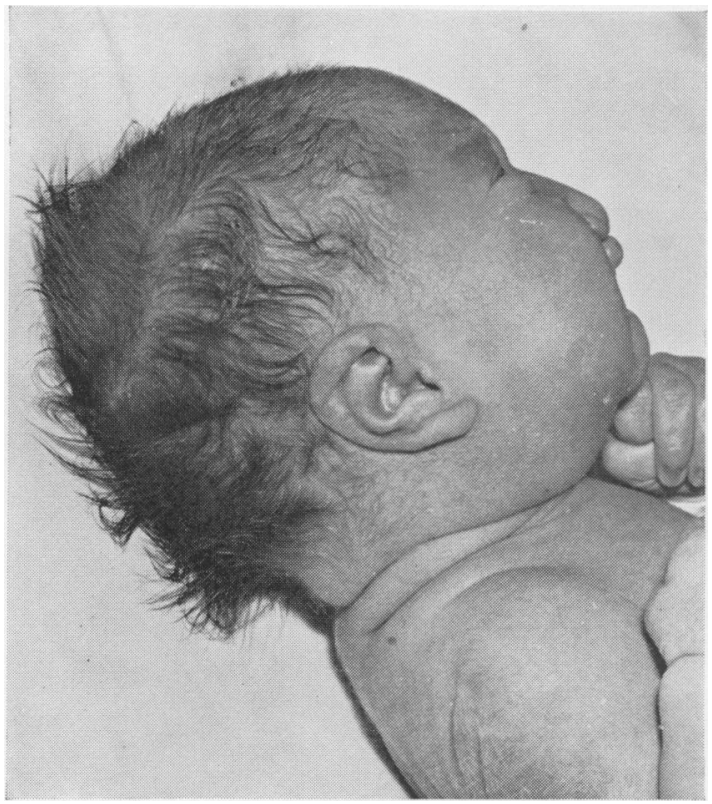

Fig. 2. Susan E. Facies in profile.
In the skull, the bones were very asymmetrical. The frontal bone was flattened on the left side, more so than on the right. The right parietal bone was also flattened, but the most striking thing about the skull was the large number of circular areas that had not calcified. You could see light through these when you held the bones up to the light. The largest was $2 \mathrm{~cm}$ in diameter and they were generally distributed all over the bones of the skull. The heart was a large one; it weighed $21 \mathrm{~g}$. There was dilatation and hypertrophy of the right ventricle and also a certain amount of increase in size of the left ventricle. There was a high ventricular septal defect which was $0.5 \mathrm{~cm}$ in diameter and also a large atrial septal defect. The lungs were severely congested. In the genito-urinary apparatus I found an absent right Fallopian tube and ovary. Elsewhere, apart from the liver being slightly enlarged, the other organs appeared normal and I thought death was due primarily to cardiac failure as a result of the septal defects.

Dr WooD: The other child whom we found to have many major congenital abnormalities was born in the middle of August 1965 and this was Nicola McD. She was a first child born to a mother aged 19 and a father in his middle twenties. The mother had been well apart from pyelitis 2 years previously and she had had a nephrectomy because the right kidney was thought to be hypoplastic. Her pregnancy was uneventful although she had a slightly high blood pressure, $140 / 90 \mathrm{mmHg}$ towards the end. She had $X$-ray pelvimetry at 36 weeks, but no other interference of any kind. The baby was born by assisted breech delivery at 39 weeks and the birth weight was $4 \mathrm{lb} 8 \mathrm{oz}$. There was foetal distress and, once again, it was obvious that this was a very abnormal child. The head was long and narrow with prominence of the occiput and keeling of the frontal bone.

This was the child's face (Fig. 3). I think that the right facial weakness is probably related to delivery and not to the child's other condition. The bridge of the nose is, perhaps, rather obvious for a newborn and in this view you may be able to see an unusual ear on the left side, the right one being virtually normal. Here one can see a left arm with very marked flexion deformity of the wrist amounting to about 100 degrees (Fig. 4). The thumb was dislocatable on extension and the fingers showed radial deviation. There was a certain amount of crepitus over the proximal third of the radius, but we were unable to demonstrate radiologically any fracture there. The sternum was rather short 


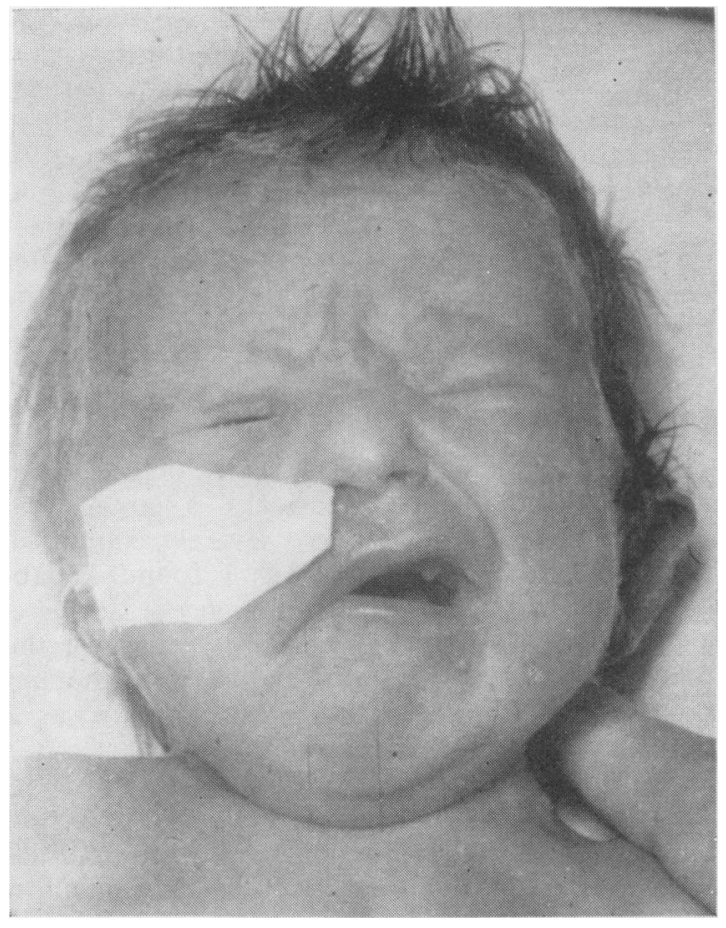

Fig. 3. Nicola McD. Front view of face.

and the front of the chest flat. There was no umbilical hernia and the abdomen seemed to be normal. The legs were grossly abnormal, however, in that the left hip was frankly dislocated and the right hip showed very limited abduction. There was gross bilateral talipes equino-varus (Fig. 5) and a dislocation of the right knee. Clinically the upper part of the tibia lay below and behind the lower end of the femur and one was unable fully to extend the leg at this joint. Apart from the gross skeletal abnormalities, the great toe seemed to come off the base of the second toe on both feet and to be smaller than one would normally expect (Fig. 5).

In addition to these external appearances, this child had a systolic thrill in the left praecordium and a grade $4 / 6$ pansystolic murmur, and one felt certain that this must be a large septal defect. Like the other child she did very badly and over the first 4 days of life her respiratory rate went up, she had some fits and she gained weight rapidly. The liver became palpable and she developed congestive cardiac failure. She died when 4 days old and, once again, we were able to send material to Professor Polani and we had a post-mortem done.

Could I ask Dr Rubin to tell us about her $\mathrm{X}$-rays?

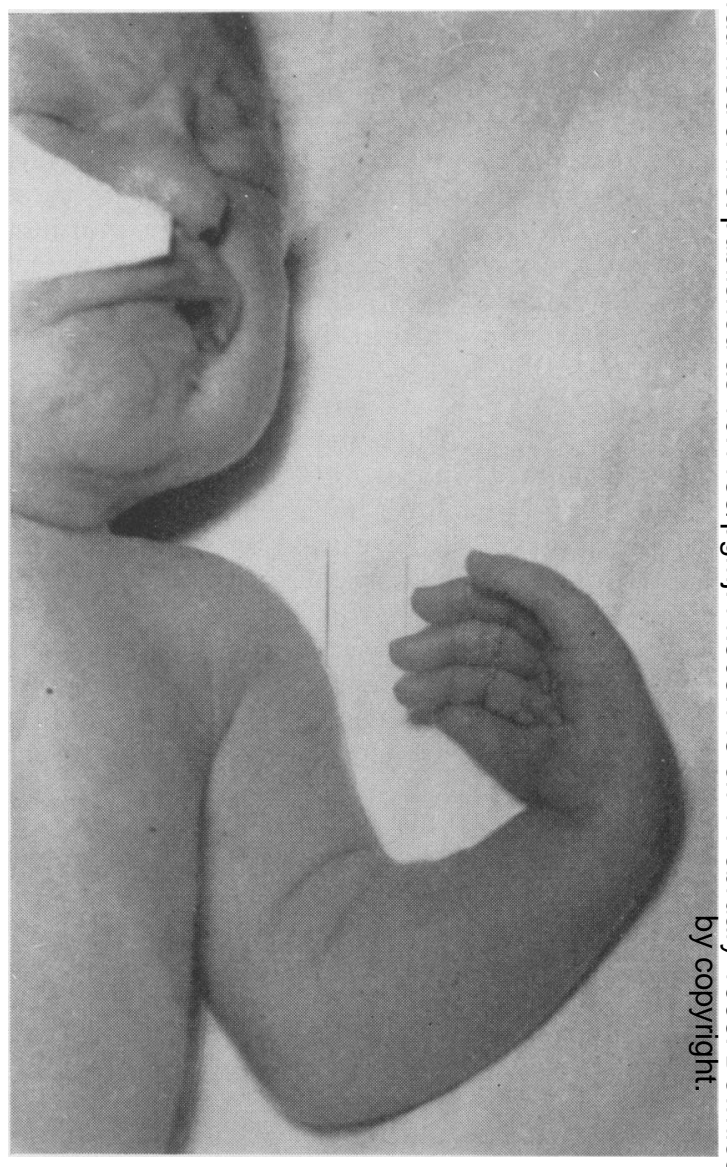

FIg. 4. Nicola McD. Left arm with flexion deformity at wrist.

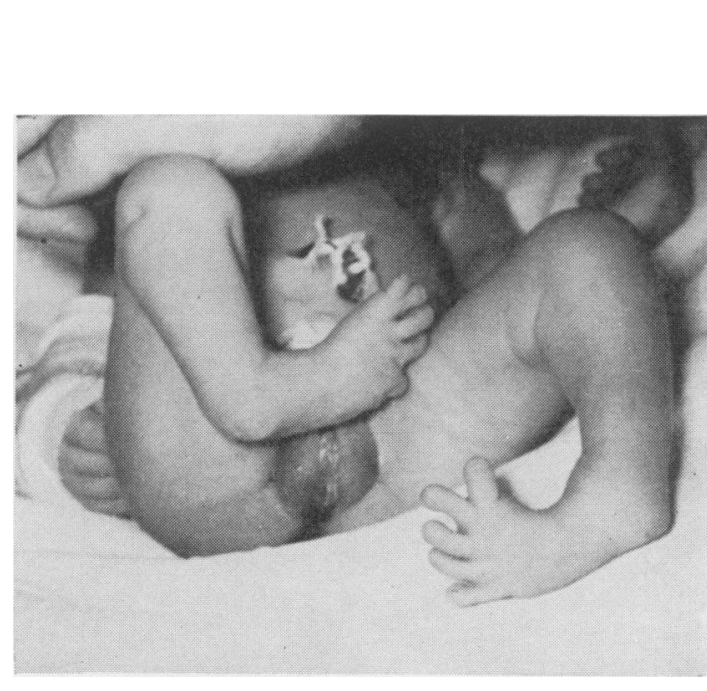

Fig. 5. Nicola McD. Bilateral club feet. Abnormal origins of great toes. 


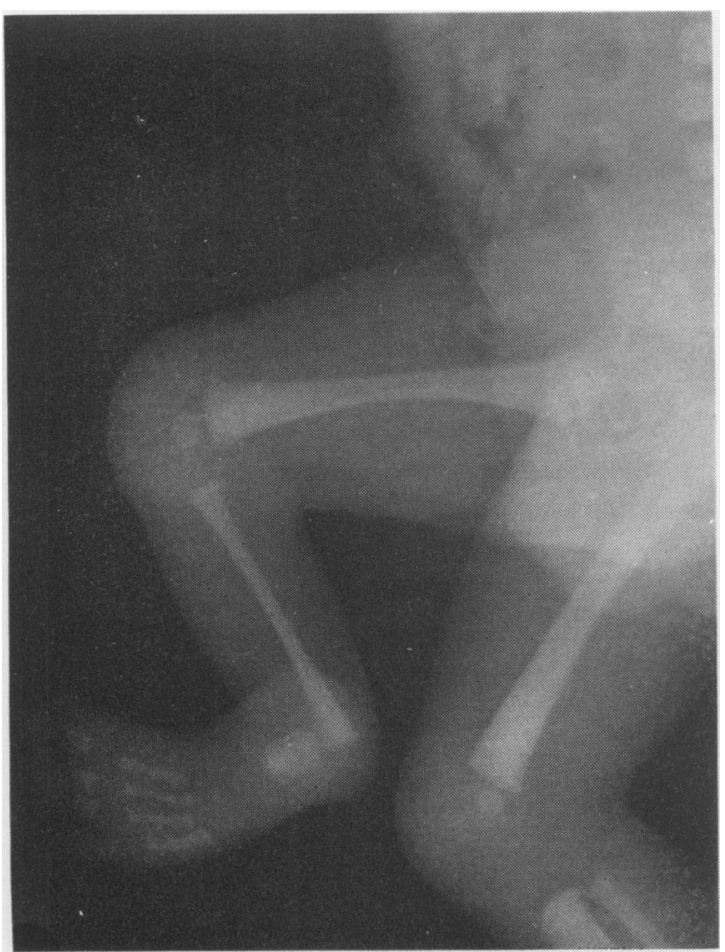

Fig. 6. Nicola McD. Single fibula-like bone and only four metatarsals (right leg).

Dr Rubin: All these films were taken in the ward when Nicola was about 7 hours old. Her skull is smaller than average for a neonate and I would say it is microcephalic. The cardiac shadow is exaggerated by the portable technique but it appears enlarged.*

The most severe changes are in the limbs (Figs. 6 and 7). The single right lower leg bone looks like an elongated fibula and there are only four metatarsals. The left tibia is malformed, bowed and shortened and there is talipes.

The hips have been examined in the abducted position. The left dislocation is not well shown.

Dr TROTT: Briefly, at post-mortem there were abnormalities in the skull which consisted of flattening of one side of the occipital bone and similar changes in the heart to those seen in Susan E. The right ventricle was dilated and hypertrophied, and was larger than the left one, and there was a high ventricular septal defect and an atrial septal defect as well. Apart

* The ribs and clavicles are slender and slightly irregular as described by R. Astley (1966) Brit. J. Radiol. 39, 86. from these changes, the kidneys were both very small; one weighing $4.5 \mathrm{~g}$ and the other $3.5 \mathrm{~g}$, but they appeared macroscopically normal. Death, I thought, was due to the congenital heart lesions.

Dr ManN: Perhaps Dr Meadow could present the next case, please.

Dr S. R. Meadow: Baby A. was born a week ago and was to be the baby we hoped to show you in life, but unfortunately he died 2 days ago. His parents are both in their early forties. They had two children when they were first married-when they were in their early twenties -which were normal, and since then Mrs A. has had one miscarriage and a premature delivery of very tiny twins who died soon after delivery. This pregnancy was normal, as was the delivery, and the baby was born at full term. Birth weight $6 \frac{1}{2} \mathrm{lb}$. At birth it was apparent that the infant was very abnormal (Fig. 8). The main abnormalities were that it had a receding brow and a very short neck. It was hunched up

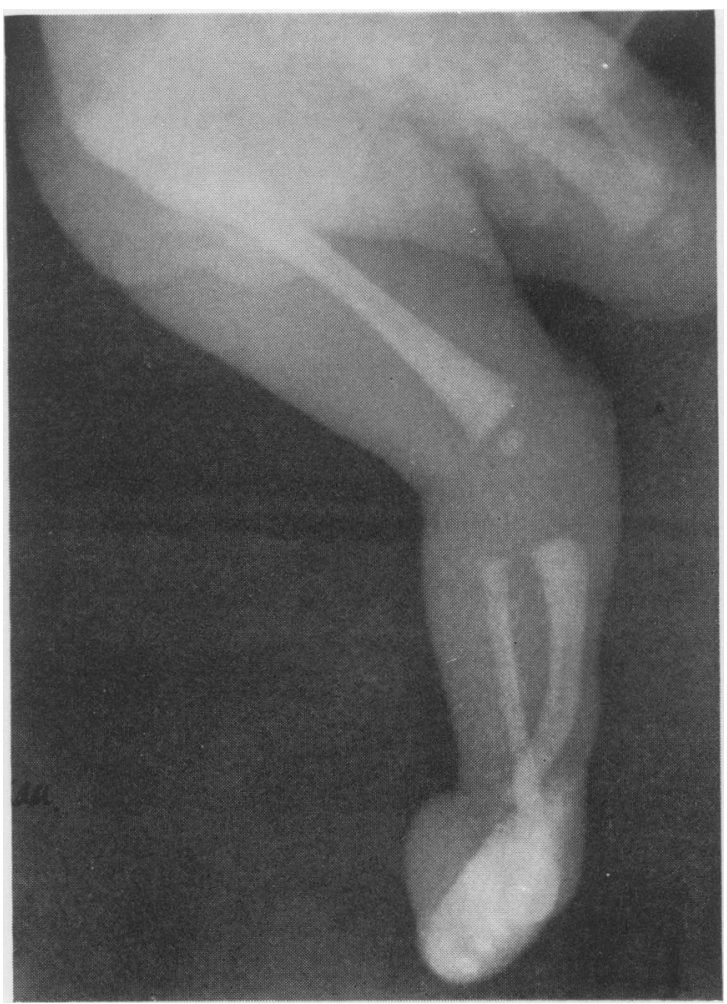

FIG. 7. Nicola McD. Deformity of left tibia and talipes. 
with great folds of skin coming down from the occiput to the shoulders. It had tiny widely spaced eyes with tightly screwed up lids. The nose was broad with a depressed bridge. There was a very small mandible with a complete cleft palate. There were funny little ears, all twisted up at the side (Fig. 9), the chest was much bigger than in a normal baby with a short sternum and widely spaced nipples and the fingers were held in a very unusual position. Instead of being clenched normally like a newborn baby, they were extended at the distal interphalangeal joints and flexed at the proximal ones (Fig. 10). The fingernails were long and hyper-convex. The axial triradiate of the palm was displaced distally and the ATD angle increased. The fingers did not show an excess of arch patterns. The genitalia were grossly abnormal and there was some difficulty in deciding if this was a boy or a girl (Fig. 11). There was a tiny rudimentary penis, virtually no scrotum at all and only one palpable gonad which was in the left inguinal canal. The feet and legs looked normal. The baby did not behave normally and from an early time had some respiratory distress with indrawing of the ribs and sternum. This increased and the baby became blue. Clinically

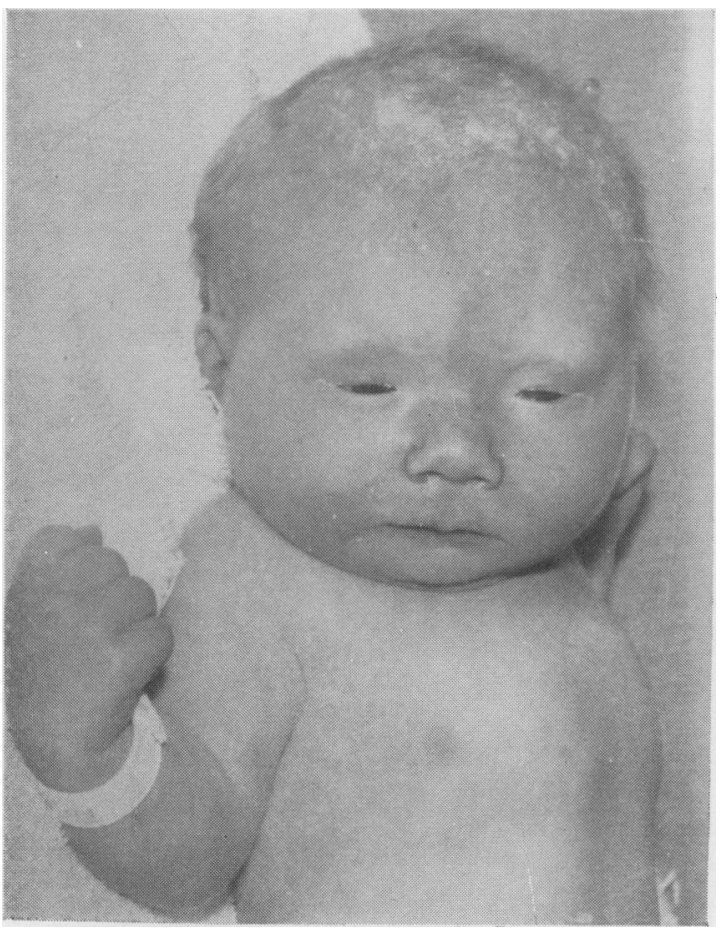

FIG. 8. Baby A. Facial appearance.

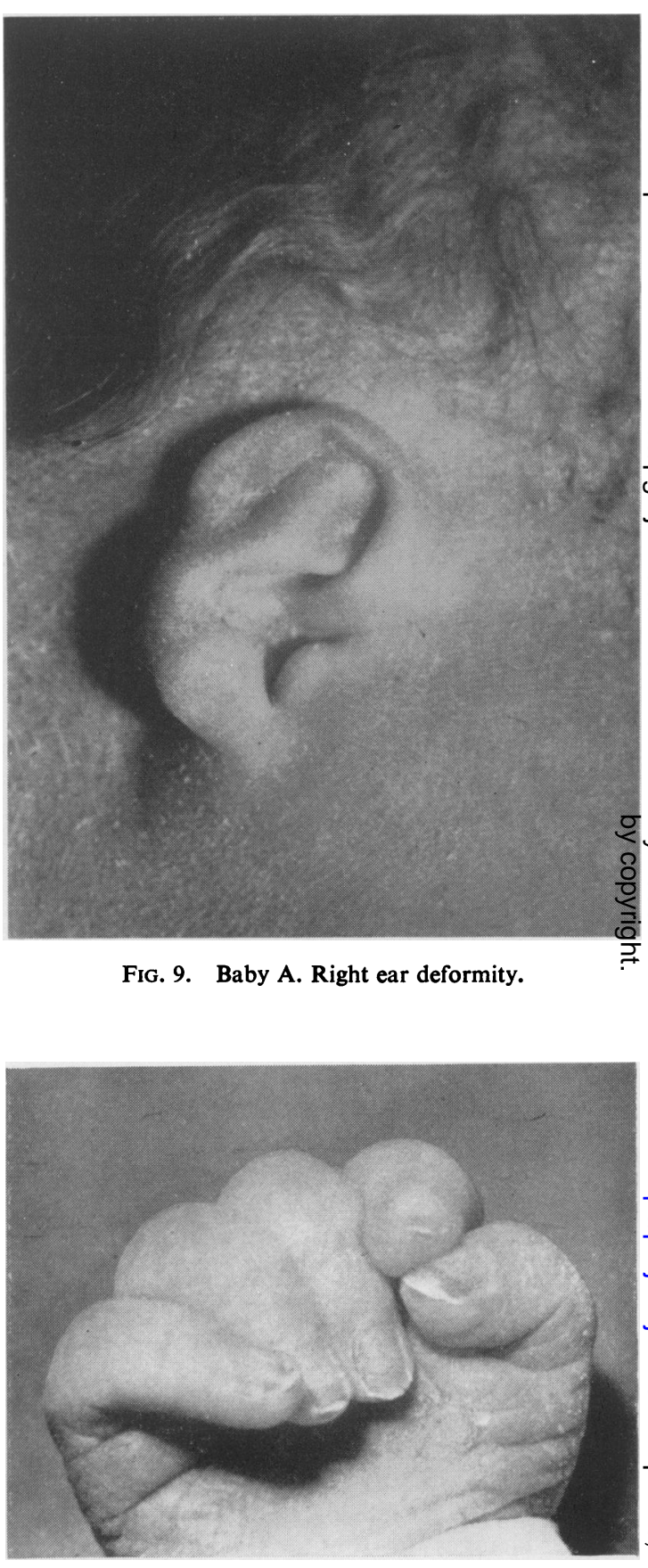

Fig. 10. Baby A. Abnormal posture of fingers of right hand.

it had a very large heart, although we could not hear a murmur, and its condition gradually $\mathscr{D}$ deteriorated over its 5 days of life and it died the day before yesterday. X-rays were taken 


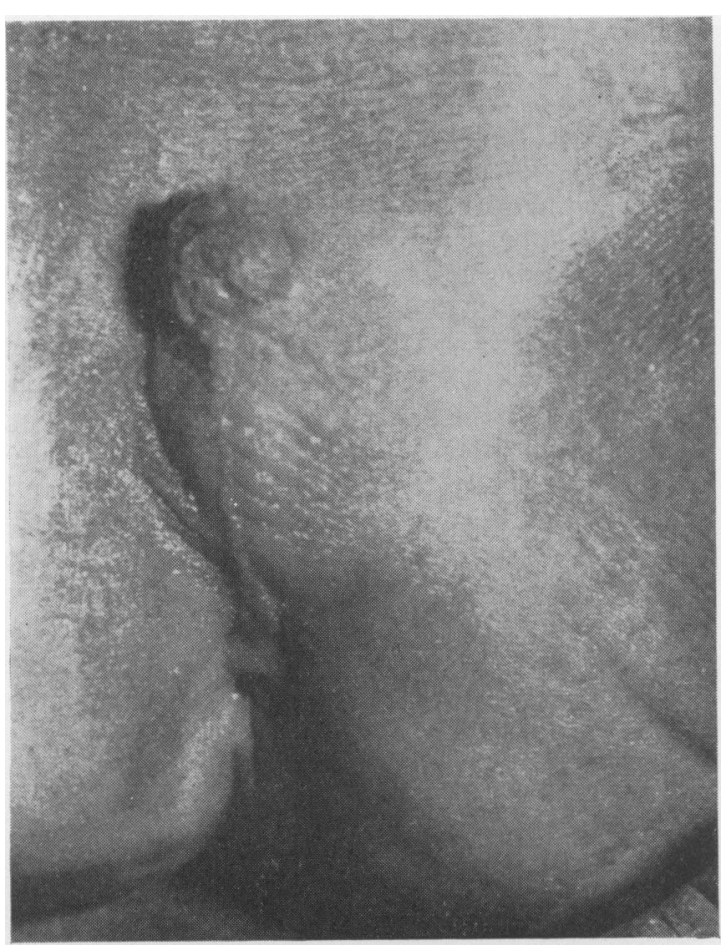

Fig. 11. Baby A. The genitalia.

and specimens were taken for chromosome study. As regards diagnosis, this baby did seem to have features in common with the two cases $\mathrm{Dr}$ Wood has presented. His, I gather, are fairly typical of the two syndromes concerned. This one, however, seemed somewhat intermediate. I think really it was most similar to the first case he presented.

Dr Rubin, I think, has some X-rays to show.

Dr RuBin: Once more we have a case of microcephaly, but the skull is symmetrical in shape, and here we have a much more severely enlarged heart with increase in the air content of both lungs due to the respiratory distress, but not much congestion. With regard to the short neck, the films do not confirm that there is any abnormality of the cervical spine.

Dr TroTt: The congenital abnormalities were as described. On the head, over the right side of the skull extending on to the forehead, the skin was a diffuse blue colour having the appearance of a capillary haemangioma. The cleft palate was a bilateral one. We have dissected the chest to demonstrate the heart which was enlarged. The right ventricle was larger than the left one although both ventricles were larger than normal and there was a patent atrial septal defect. There was a Meckel's diverticulum. The penis was small, the scrotum poorly developed. The left testis was in the inguinal canal; the right was not found, although the spermatic cord was identified in the canal on that side. I should also mention that there were two umbilical arteries. Examination of the buccal smear for Barr bodies was negative.

Dr T. P. ManN: I want very briefly now to present two further children with multiple congenital defects, both of whom have quite obviously got identical faces.

The first one, a male, David W. was born at home in June 1962 and died in August of that year. He was born at home and died at home. He was in this hospital during June, July and August. Birth weight $4 \mathrm{lb}$. The placenta was small, complete, with several infarcts. The pregnancy was quite normal. The baby gasped soon after birth and was admitted to Cuckfield Hospital on the day of birth because of prematurity and stridor. Micrognathism was a very prominent feature when the child was referred, and a small skull was mentioned. When the child came in we found he had a very strange facies, a cleft palate and a cardiac murmur. He was admitted to the Children's Hospital when he was 7 days old from Cuckfield. He had stridor, a low-pitched, croaking cry, a very large face compared with his small cranium and rather protruding eyes. His scalp and forehead were excessively hairy. There were very impressive eyebrows, long eyelashes, the micrognathism already mentioned, a rather short neck, small hands which were rather clumped with axial deviation and very small feet. A murmur was heard diffusely over the praecordium. The palate was cleft, both hard and soft, and the child, a male, also had mild glandular hypospadias. Those were the defects which we saw. I think Dr Elliott can add to them in a moment. Perhaps I could just show you the child's face and point out one or two features.

Here is this very odd looking baby (Fig. 12). We had never seen a baby like this. This was in 1962. Note the hairiness with hair coming down on the forehead-these rather prominent eyebrows-particularly laterally-this beaked-cumsaddle nose-the very long eyelashes-the rather baggy eyelids-this very broad and expansive upper lip and this rather slit-like, thin, narrow mouth and the chin which you cannot see on this picture. I want you to note the fingers on the right hand showing axial deviation. Figure 13 shows the receding chin and also this very odd 


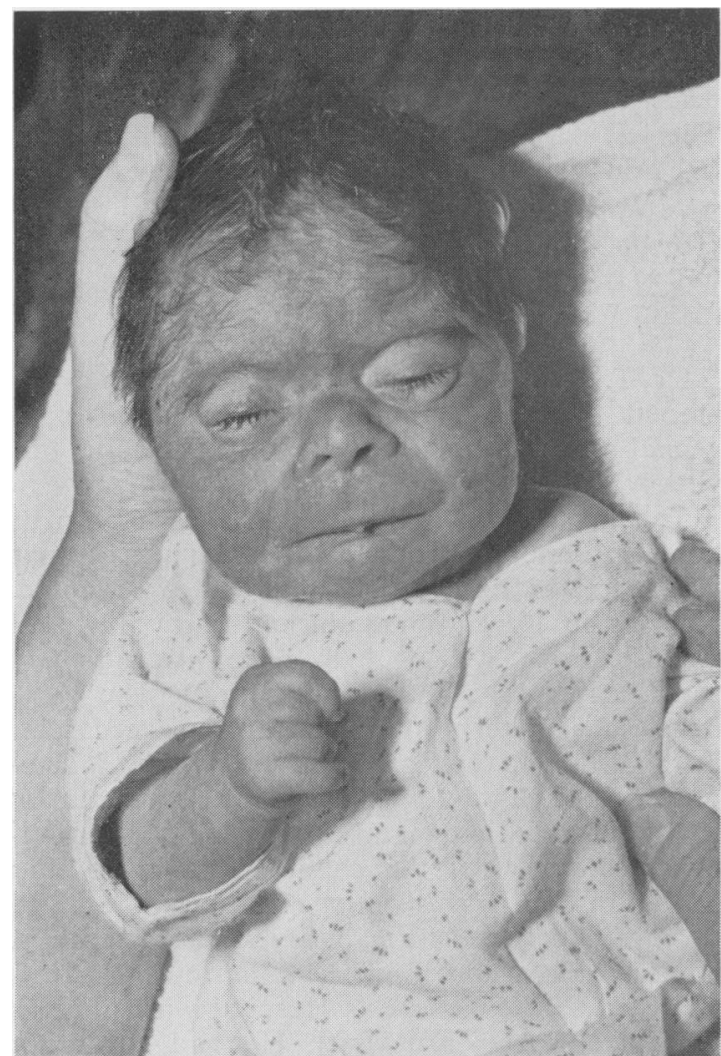

FIG. 12. David W. To show typical facies and axial deviation of fingers of right hand.

nose. I think you can see these very artificiallooking eyelashes, this enormous upper lip and another feature $I$ want to mention, in contrast to the small lower jaw, is the very prominent maxilla. Now this baby puzzled us and we asked Professor Polani to carry out chromosome studies for us. We also took these photographs which were sent to him. However, as I have already mentioned, the baby died when 4 months old and perhaps Dr Elliott would like to add to the list of congenital malformations.

Dr R. I. K. Elliotr. The brain was rather small, but it showed a normal convolutional pattern, quite well developed. There was no evidence of birth injury. The pituitary and thyroid glands were small, but macroscopically and microscopically normal. The thymus was of average size. The lungs were quite well aerated with no pleural effusions. The heart was of normal size for the child's age with a ductus which was quite prominent, but firmly closed. There was a ventricular septal defect in the upper part of the

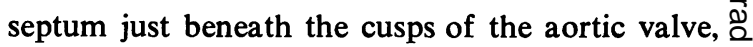
and there was fibro-elastosis of the chordae of $z$ the tricuspid valve in the neighbourhood of this $\stackrel{\varnothing}{\varrho}$ defect. The right ventricular muscle was hyper- $c$. trophied to almost the thickness of the left, and $\overrightarrow{\vec{F}}$ the foramen ovale was still patent. The coronary vessels were of normal distribution and appeared healthy. The lower end of the oesophagus showed $\frac{\bar{\sigma}}{\bar{\omega}}$ some apparent thickening of the muscle and the $\frac{\pi}{\widetilde{D}}$ stomach was small, contracted and also appeared $\triangle$ very thick-walled. The caecum was on a free $\infty$ mesentery up to the middle of the ascending $\overrightarrow{0}$ colon, so that the ileocaecal portion of the intestine was freely mobile. This is not an un- $\vec{\omega}$ common deformity, which occurs in quite a number of babies without any other deformity. The liver, spleen, pancreas and genito-urinary tract appeared normal macroscopically ; in fact microscopically there were some retention cysts in the cortex of the kidney, but the number of functioning nephrons was not reduced. The genitalia were male, there was a short penis with hypospadias; the right gonad was at pelvic brim level and the left gonad had been removed prior to

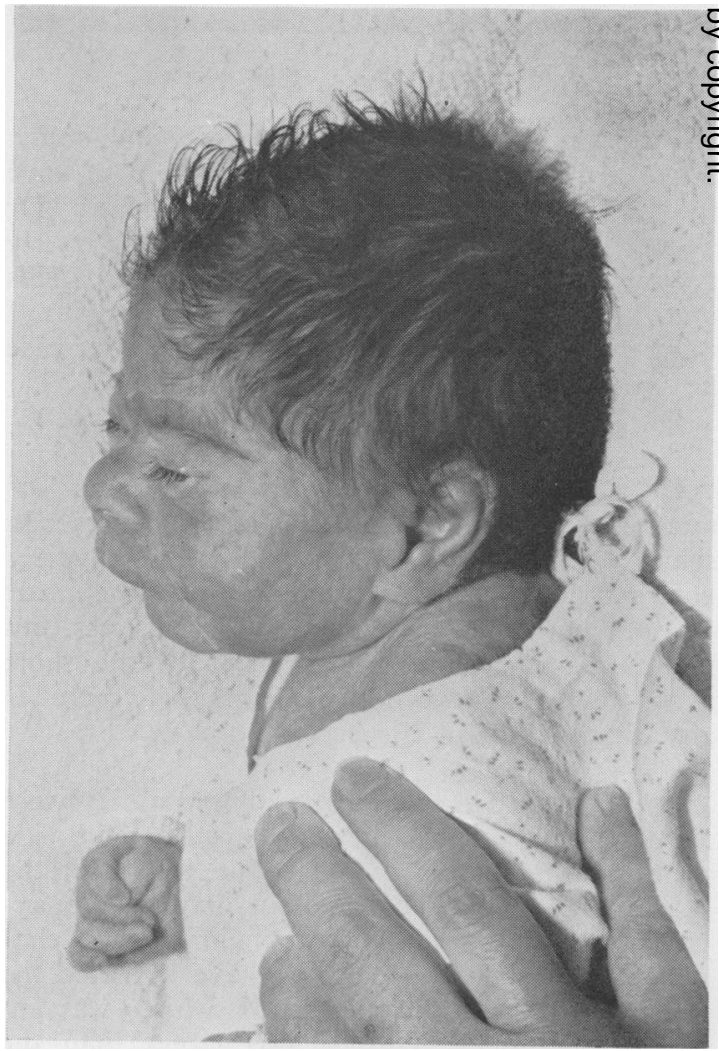

FIG. 13. David W. Face in profile. 
autopsy for chromosome studies. The remaining gonad microscopically was a testis.

One histological point of interest in this child was a curious banded pattern of the circular muscle of the stomach and oesophagus, which I have not seen before. I don't know what it means, but there was also a good deal more muscle in the stomach and oesophagus than one normally finds. The lungs showed scattered foci of alveolar infilatration by foamy macrophages due, I think, to lipoid pneumonitis. The cause of death in this child was a little difficult to establish. The presumption which I made was that it was a conduction defect related to the ventricular septal defect.

Dr ManN: The second child (Susan C.) was born at Lewisham Hospital. Birth weight $3 \mathrm{lb}$ $9 \mathrm{oz}$, the gestation period being 36 weeks. The infant was noticed to have multiple congenital defects, bilateral upper limb hemimelia, haemangiomata, hypertrophy of the labia minora and the very odd facial appearance which perhaps we can now see (Fig. 14). This was a case of Dr Bruno Gans, and being puzzled by it he also consulted Professor Polani. You will see the striking resemblance between these two babies.

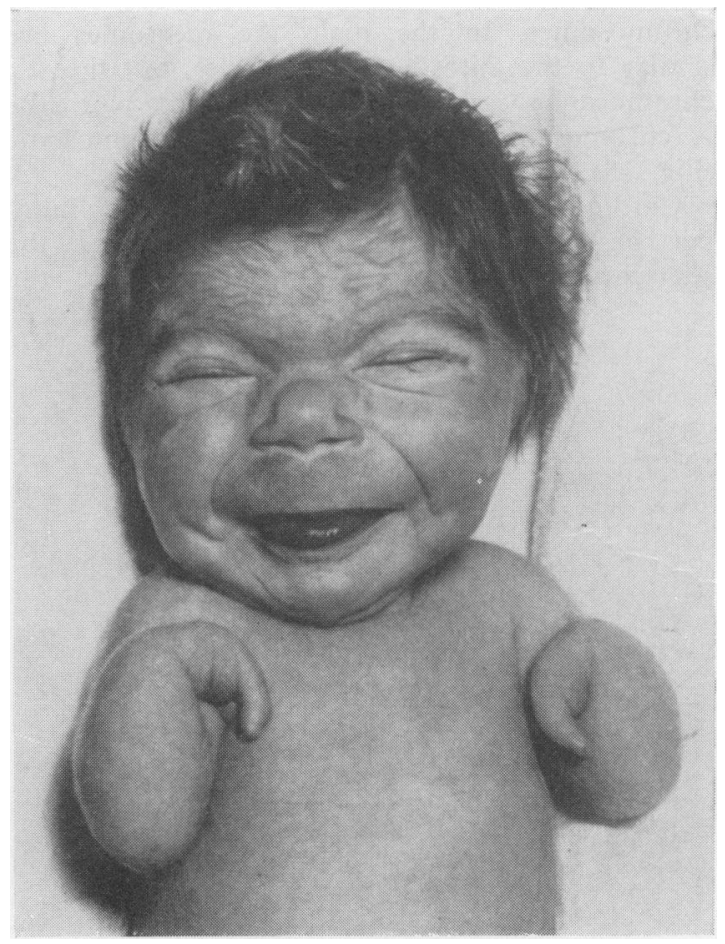

FIG. 14. Susan C. To show facies and limb deformities.

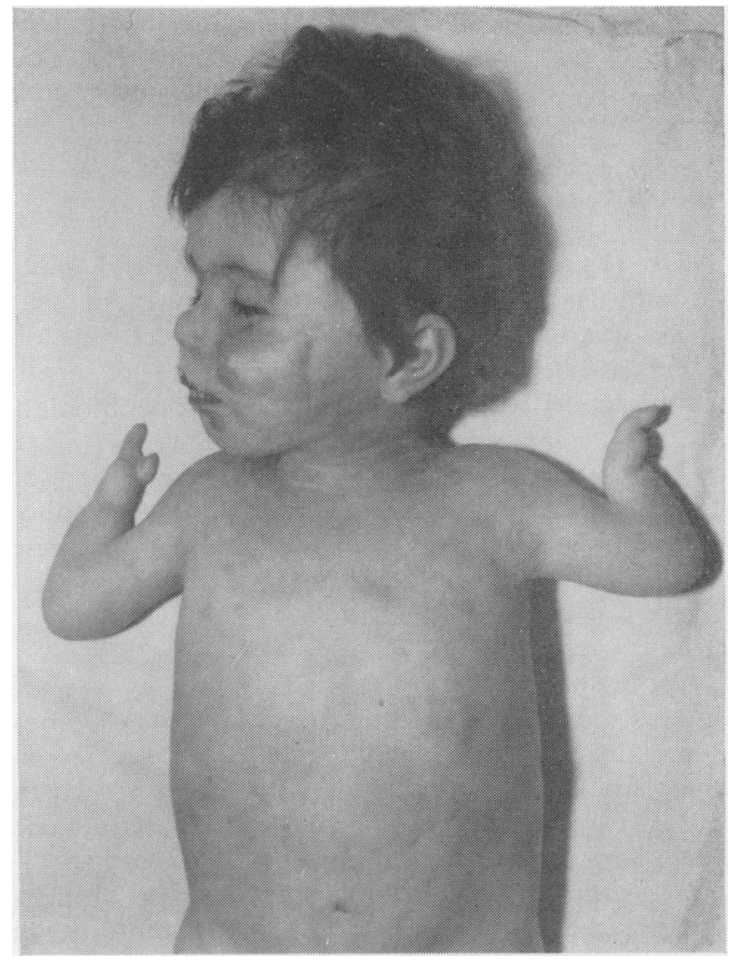

FIG. 15. Susan C. Post-mortem photograph aged 2 years.

I will not go into all the features, but you will notice that these two babies are almost identical in facial appearance. Observe the saddle nose, the prominent eyebrows, the baggy lids, this very striking expansive upper lip, the rather narrow brow and receding chin. Now this baby at the age of 34 weeks had been vomiting a lot up until this age when definite peristalsis was noticed and a pyloric tumour was felt. Ramstedt's operation was done and at this operation the surgeon found the child had a malrotation of the midgut, but he did not feel like embarking on any major surgery. I should mention that this child, when it was born, was repellent to the mother and she rejected it. The father, on seeing the baby, had a coronary occlusion on the spot and died. It went to Chailey Heritage and at the age of 2 it was brought into the Children's Hospital in a moribund condition having vomited, and died within a few hours of admission. I should mention that chromosome studies have been done on these two babies as on the previous three by Professor Polani.

This is the appearance at the age of 2 (Fig. 15), a post-mortem photograph. Note this extraordinary looking prominent cheek, the receding chin and the conspicuous upper lip. It looks as 
if someone has grafted a cheek on there. This was the appearance when she came in. You will notice the long eyelashes and the upper limb deformities.

Could you, perhaps, add something to this last case, Dr Elliott?

Dr ElliotT: I think the only thing I have to add is that $I$ did find at post-mortem that there was a bicornuate uterus, but there was no other internal abnormality. The cause of death in this child was obviously broncho-pneumonia.

Dr ManN: I am now going to ask Professor Polani to say something to you about chromosomes in general and then to comment on these cases, from all of whom he has received specimens for chromosome study.

Professor P. E. Polani: These cases are of interest in the differential diagnosis of chromosome disorders, and perhaps before I say something about the actual findings it might be worth going through, very quickly, one or two basic facts about human chromosomes.

The normal chromosome complement of man is forty-six. The chromosomes can be quite easily studied in dividing cells but you cannot see them in resting cells. One generally has to stop division at the right moment when each chromosome has made a replica of itself and is made

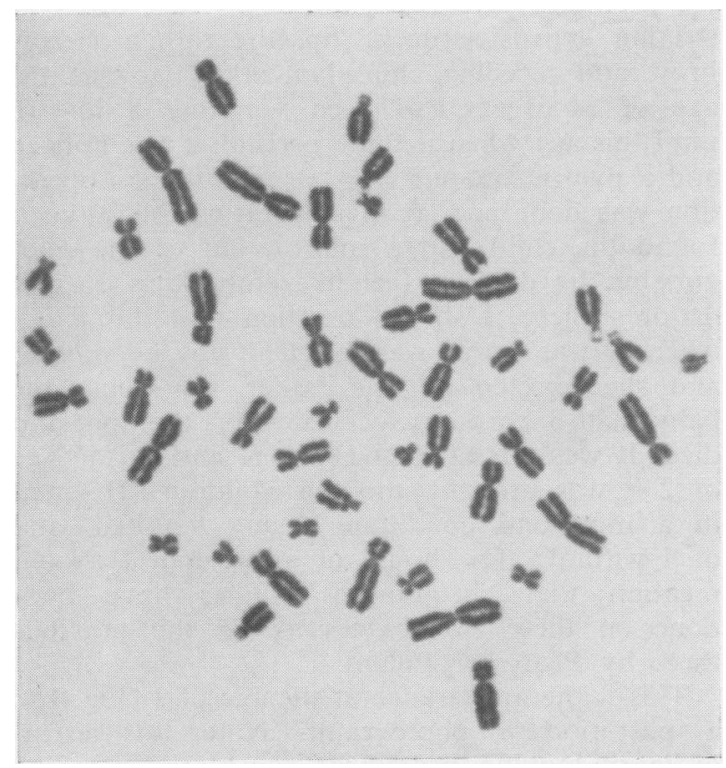

FIG. 16. Chromosomes through an oil immersion lens. up of two chromatids and consists of a double rod. The chromosomes are of variable shape and have different sizes and we can study them in short-term cultures from bone marrow or from peripheral blood, or in long-term cultures from any tissue which can be persuaded to divide, particularly fibroblasts of skin connective tissue and other connective tissues, for instance, of the gonads.

Having seen the chromosomes with an ordinary light microscope using an oil-immersion lens (Fig. 16) our object is to try and identify them and this is helped by making pairs of them. The chromosomes in humans, as in other diploid organisms, are paired; one member of each pair is maternal, the other is paternal. The method we use is very simple and a logical one. It is not a very accurate one, but for general purposes it is quite useful. It consists in matching chromosomes on two characters, the relative length of the chromosome and the position of the constriction which marks the site of the socalled centromere. This is the orderly array, called karyotype, of the chromosomes of a normal female (Fig. 17). The twenty-two pairs of chromosomes on the right-hand side are called the autosomes and the pair on the left are the sex chromosomes which have to do with primary sex differentiation. In females these are two chromosomes. In the male the autosomes are similar to the autosomes of females, but the sex chromosomes consists of an unequal pair, the $\mathrm{X}$ chromosome and the smaller $\mathrm{Y}$ chromosome (Fig. 18).

Chromosome errors can involve either number or structure. They can affect either the sex chromosomes or the autosomes, and the

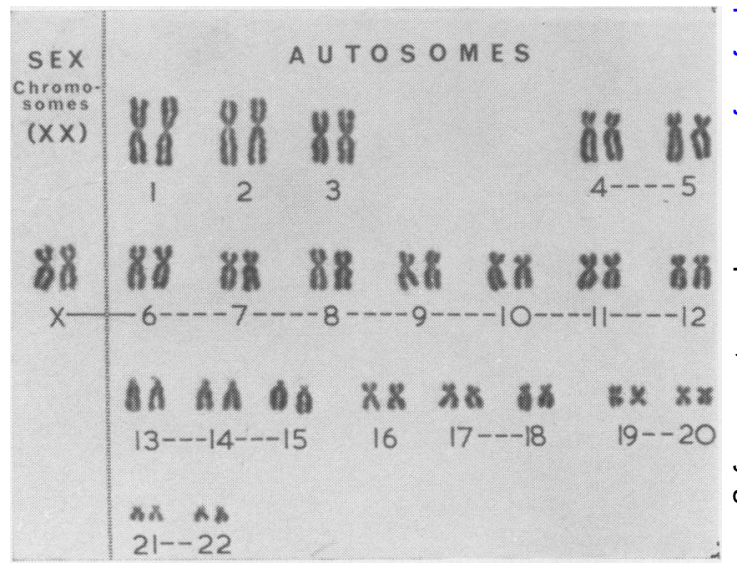

FIG. 17. Karyotype of a normal female. 


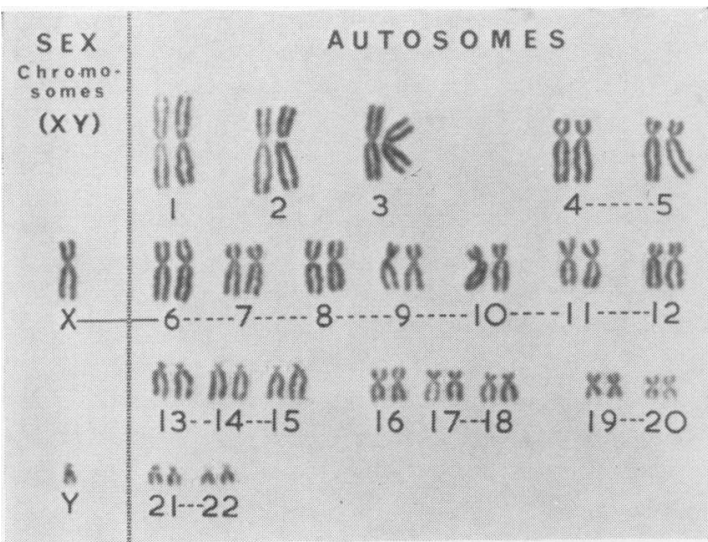

Fig. 18. Karyotype of a normal male.

cases that have been presented today fall under the category of errors of the autosomes-generally errors of number. There are really three main errors of number of the autosomes that can occur in man and are compatible with survival at birth. The commonest is the presence in triplicate of a chromosome 21 so that we have forty-seven instead of forty-six chromosomes; this, trisomy 21 , is the cause of Down's syndrome or mongolism. Another condition which is, however, rarer is known as Patau's syndrome which is caused by trisomy of one of the members of the D group-we believe, chromosome 13. The third condition is the triplicate of chromosome 18. This leads to the syndrome of Edwards.

Here is the typical arranged chromosome pattern of mongolism or Down's syndrome-trisomy 21: forty-seven chromosomes in a male with three chromosomes 21 (Fig. 19). The second

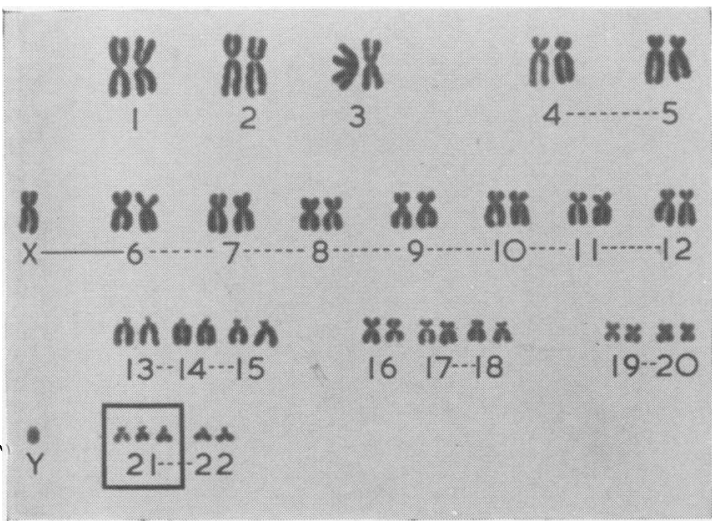

FIG. 19. Karyotype of a regular male mongol. condition is the autosomal trisomy which causes Patau's syndrome. Here is trisomy of chromosome, say, No. 13, again in a male (Fig. 20). This was the anomaly that was found, in fact, chromosomally in the first patient who was shown here tonight. The essential features were of a child deformed at birth, with hare-lip and cleft palate, congenital heart disease, an odd-looking face and exomphalos. The mother had had hydramnios in pregnancy. The baby was light at birth, his weight was $6 \mathrm{lb} 1 \mathrm{oz}$. He was born to a mother aged 41 . All these features really point to the syndrome.

There is a proportion of cases that have a number of the features of this syndrome, i.e. hare-lip and cleft palate and congenital heart disease, but without chromosome anomaly. I think this ought to be stressed. We think at the moment that probably the best diagnostic predictors of the chromosome anomaly in the two

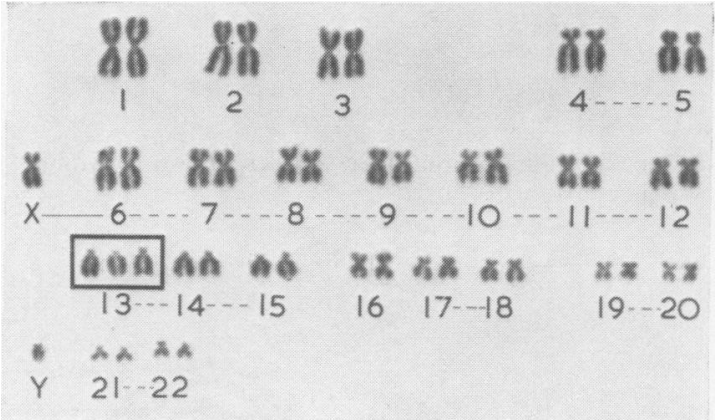

FIG. 20. Trisomy of chromosome 13 (Patau's syndrome).

syndromes of Patau and Edwards are the findings relating to the finger-prints and palm-prints, and foot-prints to a certain extent. If I may just take a minute to expand on this. The technique is simple and is what Scotland Yard does. They take a finger-print and they classify the patterns which are seen on finger-tips. These patterns are formed by the dermal ridges which correspond to the outlets of the sweat glands. You can see these ridges very clearly with the aid of a hand-lens, running parallel to each other. Figure 21 shows an arch in which all ridges run parallel. Figure 22 demonstrates a more complex pattern than the one you have just seen. Here the ridges run in a curved pattern and at this point you can see three sets of ridges meeting. They form what is known as a triradius. The pattern is known as a loop. It has one triradius and it opens to one side or the other of the finger. Here in Fig. 23 the pattern 
is more complex still and leads to a sort of bullseye on the fingertip. This pattern is called a whorl: it has two triradii.

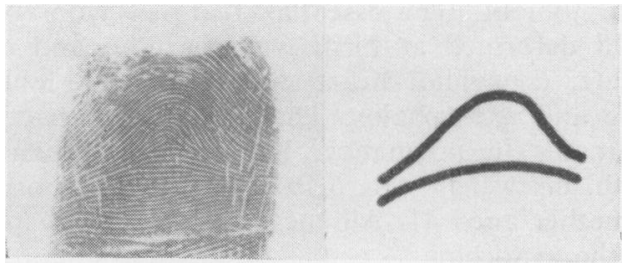

Fig. 21. Finger prints-An arch in which all ridges run parallel.

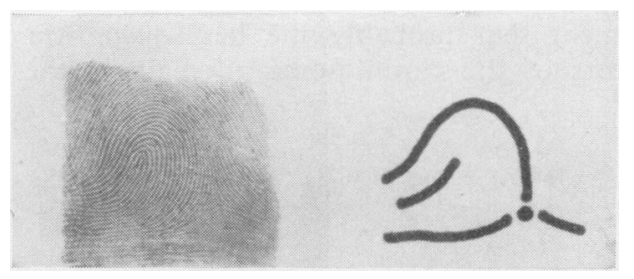

Fig. 22. Finger print-The pattern known as a loop.

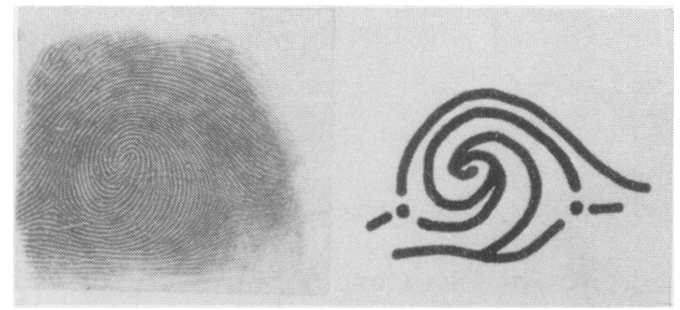

Fig. 23. Finger print-The pattern called a whorl.

Figure 24 shows a complete hand-print, and you can see the finer ridges on the palm and the patterns on finger-tips. There are triradii at the base of each finger (they have been encircled) and there is one triradius somewhere along the palm and this is normal in position. Most normal people have a triradius down here near the wrist (Fig. 24, within the circle). In some abnormal conditions, like Down's syndrome, or Patau's syndrome, this palmar triradius is displaced towards the fingers. There is a way in which you can present this more easily so that people can see it. You mark the main triradii and the main lines which arise from them. Now you can see in this palm (Fig. 25) two low triradii which is not unusual. One is at the

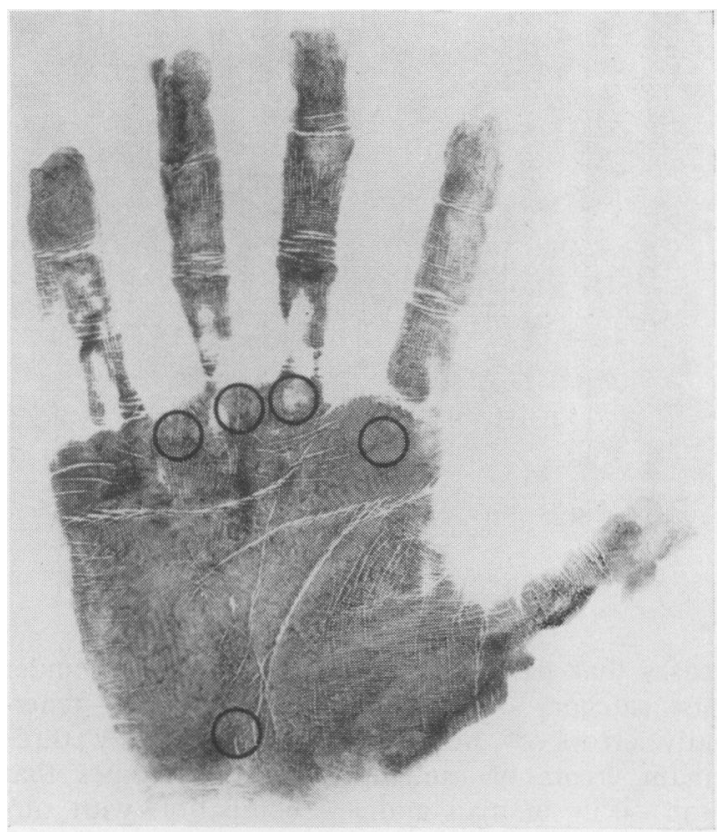

FIG. 24. A complete hand print.

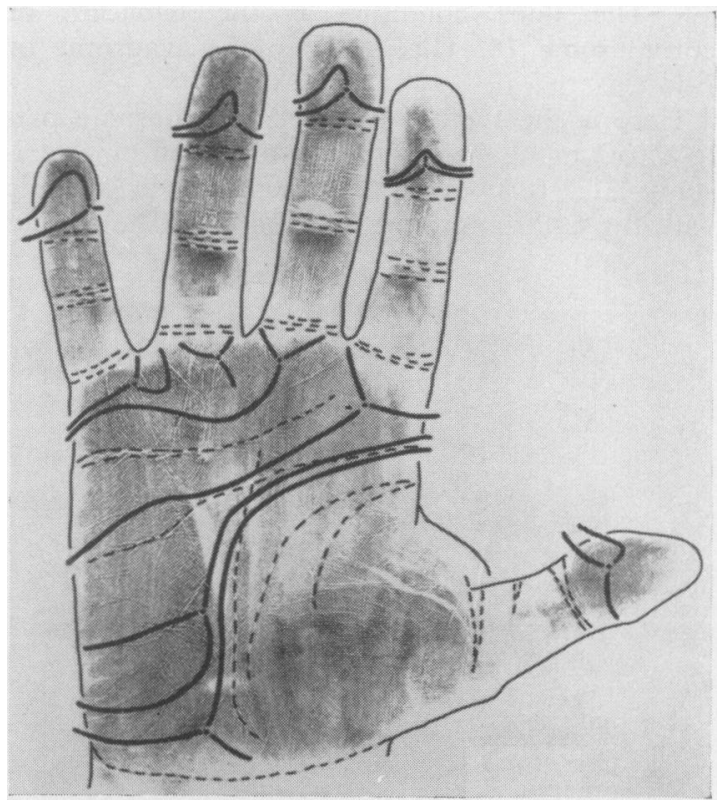

FIG. 25. Palm showing main triradii and the main lines which arise from them. 
base of the hand, near the wrist, and the other higher up. These are the axial triradii and then there is an additional triradius at the base of each finger and a pattern on the tip of each finger. If you use your finger-print and palmprint patterns as diagnostic adjuncts in the possible or probable cases, say of Patau's syndrome - the syndrome with cleft palate, hare-lip, congenital heart and other anomalies, scalp defects and so forth-then the striking finding is the fact that the axial triradius of the palm is displaced very much towards the finger tips. One way of expressing the position of this triradius is simply to measure the angle formed between the distal axial triradius and the triradii at the base of the index and small fingers. This is known as the $A T D$ angle.

A very distal displacement of the distal axial triradius produces a very obtuse $A T D$ angle. If you find this in association with the findings you have heard of today, it would be practically diagnostic of trisomy for chromosome 13 .

The third autosomal trisomic syndrome corresponds to the second case that was demonstrated here. In this syndrome there is usually a small jaw, congenital heart defects, the baby is frail, it does not thrive, spasticity may be present, it may have renal anomalies, and so forth. This is Edwards' syndrome caused by trisomy of a particular autosome: No. 18 (Fig. 26). In the baby which was described, however, there were limb anomalies which are not usually found in this type of syndrome, in which, however, one finds other limb anomalies, but not of this type. I would like to run through one or two typical clinical pictures of this relatively rare type of chromosome anomaly. A small jaw, low set malrotated ears, rabbity looking face with usually a very elongated narrow skull (Fig. 27). The ster-

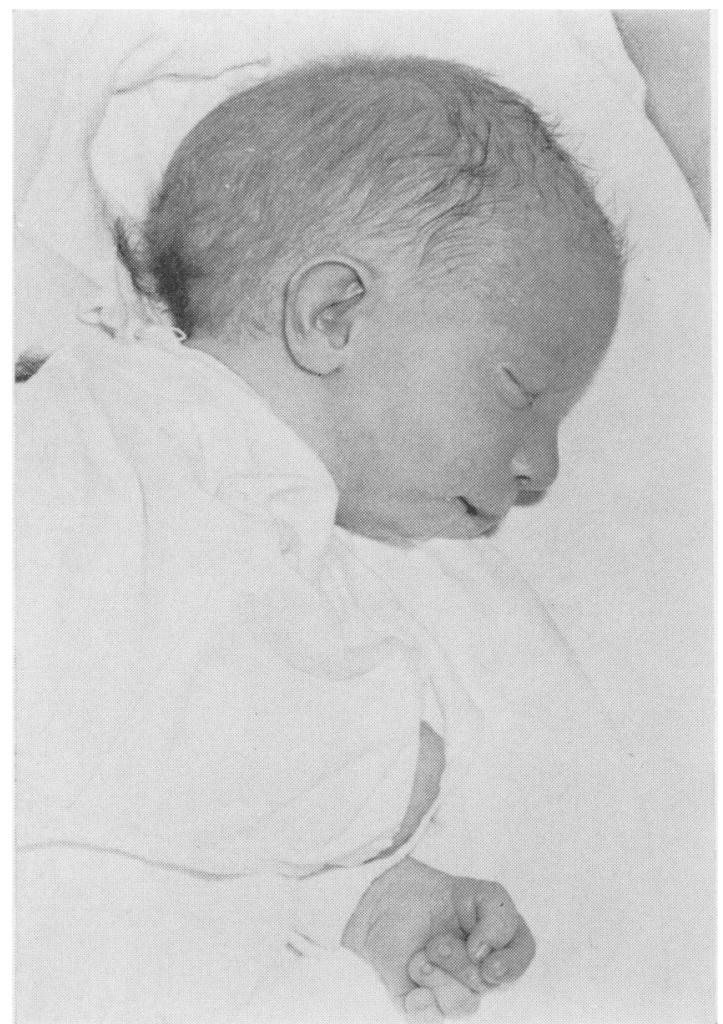

FIG. 27. Edwards' syndrome.

num is short and there is sometimes webbing of the neck; the nipples are hypoplastic and widely spaced (Fig. 28). There are additional anomalies in these babies such as congenital heart disease. As for the limb anomalies in these babies, the feature to which Dr Mann referred is 'axial deviation' of the fingers (Fig. 29). It

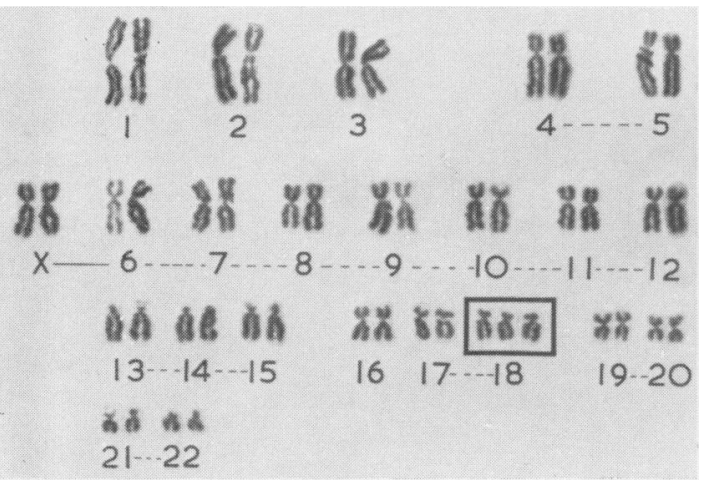

FIG. 26. Trisomy of chromosome 18 (Edwards' syndrome).

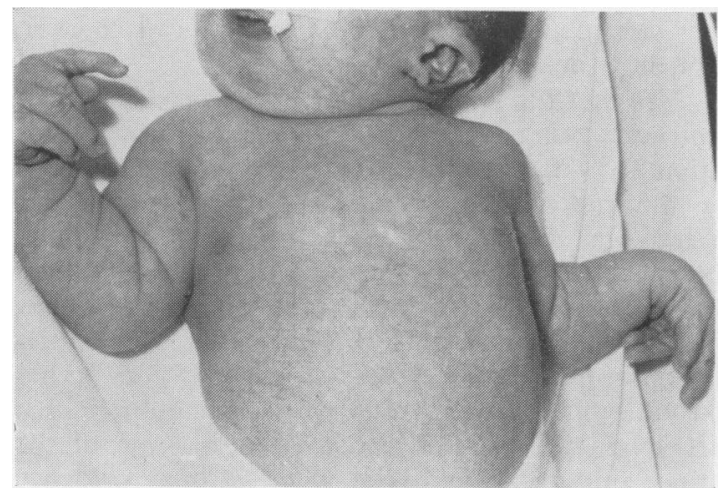

FIG. 28. Edwards' syndrome. 


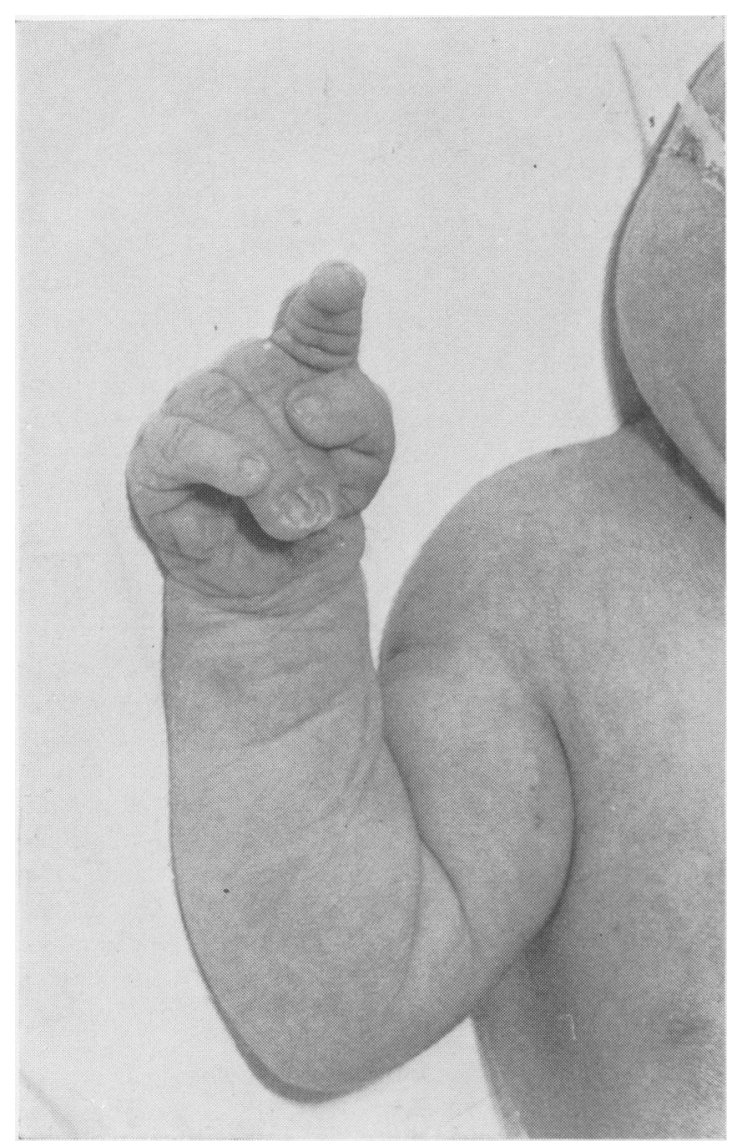

Fig. 29. Axial deviation of fingers in Edwards' syndrome.

consists really of deviation of the digits towards the middle finger. With it, very usually, there is hypoplasia of the nails and there may be other anomalies as well. A typical foot anomaly which you find is a short big toe which sticks up and pes calcaneus, which the Americans call 'rockerbottom' foot (Fig. 30).

Also in this syndrome the best predictor that you are going to find the specific chromosome anomaly-that is trisomy of chromosome 18is the pattern of dermal ridges on finger-tips. What you look for is a large number of arches. Normal people very seldom have more than three or four arches on their ten finger-tips. They mostly have loops or whorls, but in these babies it is not unusual to find as many as ten arches on the finger-tips and, perhaps, another ten arches on the toe-tips and this, with some of the other findings, would be very strong evidence that trisomy 18 is present. I gather that in the second infant you showed us today there were not, in fact, arches on the finger-tips and, therefore, I would have thought that on this ground the diagnosis would have been in doubt. It turned out, in fact, that chromosomally this was not a case of trisomy 18 . Neither was the third case which you showed us today a case of trisomy 18. If I may just show two further diagrams I can summarize the main features of these two autosome anomalies 13 and 18. Figure 31 is the typical classical case of Patau's syndrome with trisomy 13 . One of the features which we have not commented upon yet is polydactyly which is usually found in these cases. Scalp defects are quite commonly found and correspond to skull defects. The eyes are widely set, usually there is microphthalmos and coloboma, congenital heart defects, renal anomalies etc. With it are the palm-print anomalies with their very distally displaced axial triradius.

This is Edwards' syndrome (Fig. 32) with the elongated skull, the small jaw, the low-set ears, the congenital heart defect, various other anomalies, the rocker-bottom feet and the axial deviation of the fingers and so on. Of course, the most important finding to predict trisomy 18 is arches on finger-tips.

Dr ManN: Thank you very much, Professoro Polani, for that masterly exposition. Before turn ing to Dr Fraser Roberts may I ask you pleaseo to say a few words about the two examples $F$

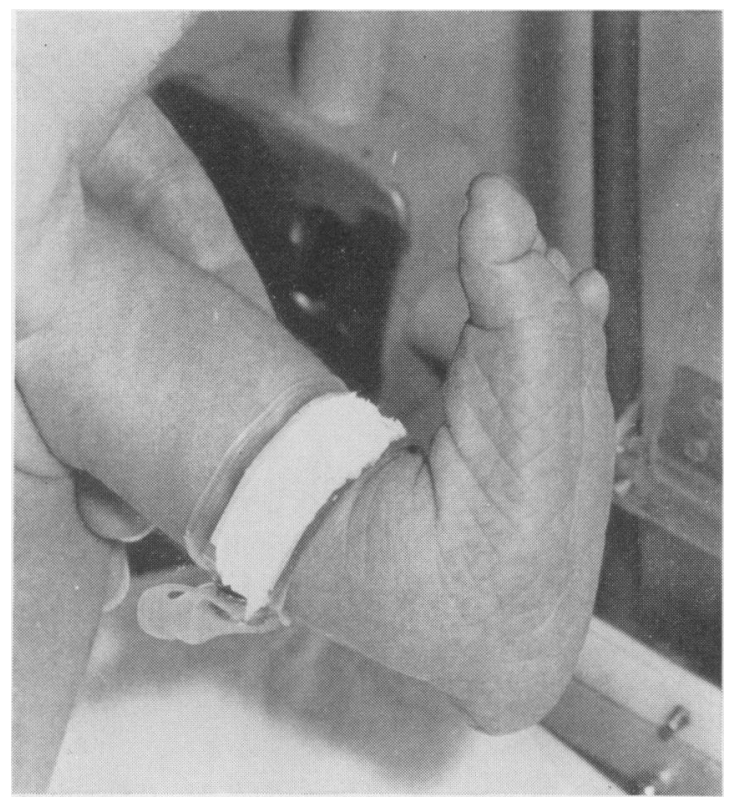

FIG. 30. Typical foot in Edwards' syndrome. 
mentioned of the Cornelia de Lange's Amsterdam Dwarf syndrome.

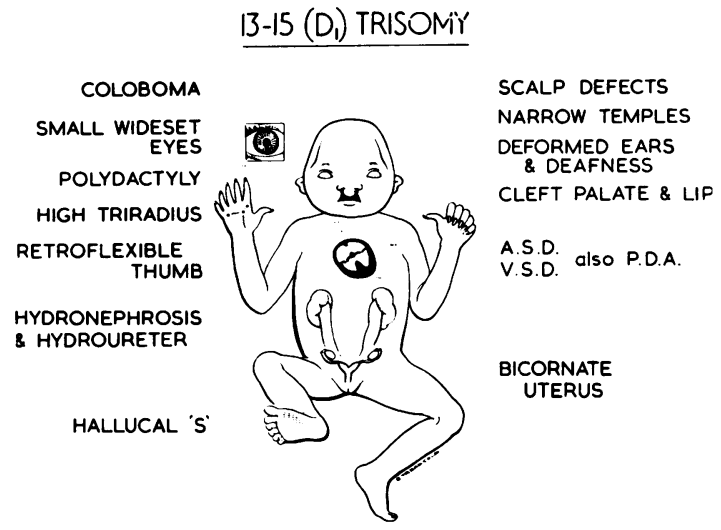

FIg. 31. Components of Patau's syndrome.

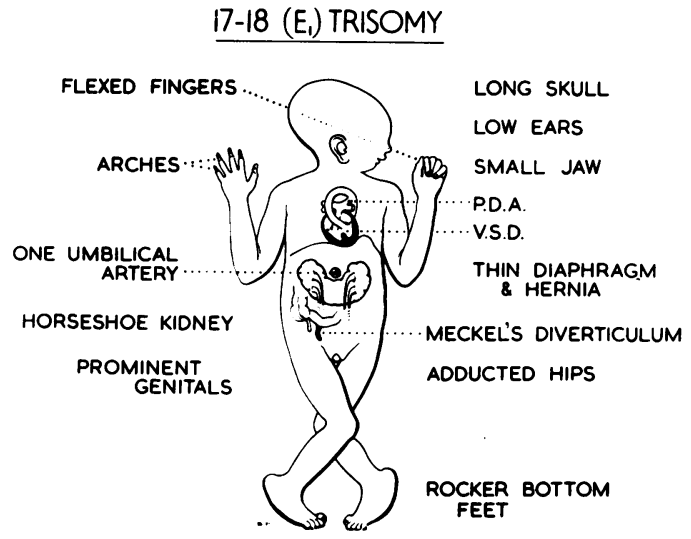

Fig. 32. Components of Edwards' syndrome.

Professor Polani: Well, in a few words, this is really a syndrome of clinical interest but we do not know its aetiology. There usually is no detectable chromosome anomaly. The most characteristic features of the syndrome are the facial anomalies which Dr Mann has discussed and which are always present in these cases. But then they must be present because this is the way you select these cases. You cannot select them in any other way. Limb anomalies are common. They need not be as severe as in the second case. Usually the hands are spatulate and the thumbs are misplaced and so on. These babies have often malrotation of the gut which leads to trouble, or duplication of the gut which usually is the cause of their death. Congenital heart disease is not invariable, but I think it has been found in these cases, and it is not unusual to find anomalies of the brain such as microgyria and so on, but this was not present in your cases.

Dr ManN: Thank you very much indeed, Professor Polani.

Of course, we are talking about rather rare defects tonight, but we do, in the course of our work, see many less severe malformations and parents, quite rightly, want to know something about these nowadays. They want to know what are the chances of having further children with further defects. Now this can be a very difficult sort of question to answer and $I$ think one must not attempt to give advice unless one knows exactly what one is talking about. Here we are very lucky in having the Guy's Paediatric Research Unit because if we have got any problems like this we can write and send the family history, describe the defect and get written advice back which we can pass on to the parents, or even better still, the parents are often quite prepared to get on the train here and go up to London Bridge and get advice at the Unit itself. Now Dr John Fraser Roberts is one of our leading medical geneticists and I am going to ask him to say something about not just these defects, but genetic counselling in general.

Dr J. Fraser Roberts: Genetic advice to parents is a thing $I$ have been very interested in for a good many years and $I$ have been doing regular genetic clinics since the last war. Now who asks for genetic advice? In our experience, and this excludes mental disease which is something quite separate, more than $90 \%$ of enquiries for genetic advice come from couples who have had a child with something the matter with it and they, or their doctors, fear that if they have another child there is a chance of the child having the same abnormality. If I had to make a very rough guess I should guess that possibly one person in forty in the population might profit from genetic advice at some time or another during their lives but, of course, as it is couples-and it may only affect one of them-one couple in twenty. I do think that the people who need genetic advice need it very badly because if doctors do not give advice to these couples you can be quite sure that they will get a great deal of very bad advice from friends, relatives and neighbours; and, as we all know, old wives' tales, usually of the most inaccurate description, do not usually err on the side of foolish optimism, so people are often left with a far gloomier picture than is really the 
true one. Now, giving genetic advice may sound rather difficult, but there are, in fact, one or two great simplifications. One is that, in general, when the outlook is bad, the genetics are simple -or rather the other way round. When you have got simple genetics as in haemophilia, fibrocystic disease, etc.-when you have something straightforward genetically, the chances are often bad-one in two or one in four and so on is a serious risk of repetition-but as the genetics become progressively more obscure, so do the empirical chances for the individual couple improve, so that let us say-just to take one or two examples-that if a normal couple have a child with a hare-lip or hare-lip and cleft palate, then the chance is about one in twenty-five that a subsequent child will be similarly affected. The chance is about one in twenty of repetition if you have one child born to a couple and the child has a spina bifida.

Then you go on to other things where the chance of repetition is smaller still, so that there is this reciprocal relationship between simplicity of genetics and the severity of the risk, so that when the risk is a bad one you usually know precisely where you are, because the genetics are simple. Then, when you really don't know where you are genetically, the empirical outlook is, in general, good. It is rather as though, reading prognosis for diagnosis, the physician were to find that all his serious cases were very easily diagnosed, but as the diagnosis became more and more difficult, so the severity of the illness decreased so that in the limit, when he had really no idea what the matter was at all, he could send the parents away quite cheerfully and say everything will be all right in a day or two. You see what a simplification this is in giving genetic advice.

The other simplification, which is an allied one, is this. In general, risks tend rather strongly to fall into two groups-the bad and the good. Let us say that a bad risk which would deter many parents from further parenthood is something worse than one in ten, and let us say that a good risk which would not deter many couples is something better than one in twenty -often much better than one in twenty. Well, it is a fact that very few estimates of risk fall in between those two regions. The risks tend to be either bad or good. This is a great help in giving genetic advice. The cases that you have been looking at tonight are cases-they are genetic, of course-I mean the chromosomal anomalies are genetic and, in a sense, grossly genetic -because here is something that is affecting not just a single gene, something you cannot pos- sibly see under the microscope-just one gene along the length of one chromosome-but something that is affecting a whole chromosome. It is a gross disorder and it is usually unlikely indeed to get any further. It is so gross an abnormality that there is the end of it. You are left with a child who may be doomed to a very early death and certainly is totally incapable of reproduction, and so to the best of my knowledge and, perhaps Professor Polani will correct me if I am wrong, with Edwards' syndrome or Patau's syndrome, I don't think there has been any instance yet of repetition at all. There is no case on record yet where parents have had two affected children, so of course you can send them away quite reassured. You never give an absolute reassurance, of course-at least I never do. One never says there is no chance of a thing happening again, but one at least can say that the chance is very, very small indeed, or shall we say no bigger than for anyone else. Of course, with the chromosome anomalies-and Professor Polani has not mentioned this-there are somewhat lesser ones where, of course, chromosomes by the process of translocation interchange segments, and then you can get the transmission through outwardly normal people-of what is really an abnormal compound chromosomeand that is why with mongolism, which has not been discussed tonight, a very small proportion is due to the presence of a compound chromosome. Here there is a rather strong risk of repetition in a subsequent child which is why, with the younger mothers of mongols in particular, those under 30 , it is advisable to carry out a chromosome study to see that it isn't one of these rather rare translocation mongols where, indeed, if one of the parents is a translocation carrier, there is a chance of repetition. But, in general, the chromosome anomalies are so severe they get no further. The sort of things that do repeat themselves are usually the single gene anomalies which, of course, are mostly rare. The commonest single gene anomaly in our population is not nearly as common as mongolism. Fibrocystic disease of the pancreas with a frequency of, perhaps, one in two thousand births is the commonest simple genetic condition in our population but, of course, there are an awful lot of them, so though individually rare, they are not unimportant in the aggregate.

The third syndrome chosen, the de Lange's syndrome, is very interesting because here is something which isn't a chromosome abnormality and there is apparently no tendency for repetition. It is the sort of thing that, on the face of it knowing that the chromosomes are 
normal, you might think might be an inherited condition, but so far as I know-and I cannot claim to be very familiar with the literaturethere is only one paper which described more than a single instance in a family group, and that is an Italian paper of some years ago where a first cousin of a patient was supposed to be affected in the same way. But the people who wrote this paper and reported the case hadn't seen the cousin personally. It was a description they were given, so you see it remains a little doubtful. So here is something where we rely entirely on empirical evidence. I think it was in 1933 that de Lange described the original cases, but a good many have been described since. However, as I say, without any indication of any other person in the family being affected, on empirical evidence, if a couple have a child with this syndrome, I think we can fairly say to them that the chance of any other child being similarly affected is extremely small. In the light of present knowledge that is what we would say. I could give you one figure, however. We have had a clinic for genetic advice at Bristol which started in 1953. Now, unlike the London clinics this was advertised to the doctors. When the clinic started all the specialists in the area were circularized and soon afterwards the opportunity was taken for bringing the existence of the clinic to the knowledge of all the G.P.s, so at least we think we are getting the cases which are likely to be referred in an area where there is a clinic which is known to everybody. The number which we have seen out of an effective population of half a million is about fifty new cases a year. That gives, I think, the measure of the problem. We are getting fifty new enquiries a year in a population of half-a-million. It is not a big demand. I certainly don't think it is the maximum which will ultimately be obtained, but it is the sort of thing you can expect under present circumstances. So, the provision of genetic advice for people who need it is not really a very big task providing there are people willing to do it.

Dr ManN: Thank you very much indeed, Dr Fraser Roberts. Could I ask the speakers to come up on the platform and then you can ask them questions.

Perhaps I could ask one question to start the ball rolling? I should like to know why it is, when children have a surplus of genetic material, a little bit of extra material, why do all these things go wrong?

Professor Polani: The straight answer is: I wish I knew! But one can hazard two guesses -in some cases maybe three-one of which is safe, and the other or others less safe. The safe guess is that whatever major genes-for making this or that polypeptide or enzyme-there are on these chromosomes, these would act in excess and probably make an excess of specific proteinenzyme. Nevertheless, because the control of protein and enzyme synthesis in complex cells is a subtle and complex matter, no simple rule can be given as to what could be expected. In other words, an 'extra' structural gene, added to the two normally present at a specific locus, need not cause the production of half as much again extra protein or enzyme.

The second guess as to how extra chromosomes may act is less safe, but I favour it especially. This appears to be a non-specific activity; in some ways it may even look as if the size of the extra chromosome may be the important thing. Well, one idea may be that what matters is the load of so-called heterochromatin on the different chromosomes. Anyway, the effect could be non-specific, quantitative rather than qualitative, affecting rates of cell division, for instance, or cell size, or membrane permeability, or total number of cells, or cell survival, or cell motility and the like. These general, non-specific, quantitative effects would be particularly relevant during embryogenesis, as they might cause retardation of growth and development, failure of midline structures to fuse and close, impairment of cell migration and division, and so on. The third guess, really only in respect to chromosome 21 and perhaps 13, is that an upset of this chromosome might produce an upset of the nucleolar organizer, which is associated with this chromosome. The nucleolus could be upset as a result of this, and we know that the nucleolus is of importance in ribonucleic acid (RNA) turnover. RNA, in its turn, is important to protein synthesis, etc. Thus this is yet a third way in which autosome trisomy might upset cell balance and function in Down's syndrome, and perhaps also in Patau's syndrome. Thus, in conclusion, we have three possible types of trisomic effects: specific, non-specific and semi-specific.

Dr Fraser Roberts: Could I add just one point to that? Surely Professor Polani would agree that the loss of a chromosome is obviously much more serious than an extra chromosome. You get very few anomalies due to the loss of a chromosome, except in the sex chromosomes, because it is lethal and never appears at all.

Professor Polani: Yes, this is certainly so. The sex chromosomes are, of course, to some extent an exception, but of the autosomes there 
is no condition known, caused by the absence of an autosome, which is viable. Not even viable as far as to lead to a recognizable pregnancy because there is no abortion which has been shown to have, for instance, a missing autosome. The only condition which is viable is a partial absence of autosomes; in other words a deletion of a small fragment of an autosome-for instance autosome 5 , presumably. This leads to a specific clinical syndrome, which appears to be very rare, called Cri du Chat.

Dr RUBIN: I am interested in the abnormalities we see where we know there has been some toxic effect during pregnancy. Thalidomide was the prime example of that and rubella is another example. I think the degree of damage may be related to the stage in pregnancy in which the toxic influence takes place. This is of relevance in the Amsterdam Dwarf, where there is remarkable symmetry in the deformities. There was bilateral fusion of the radius and ulna into a single thick short bone and there was failure of segmentation of both hands. There was only a single metacarpal from which two digits arose on the right side and one on the left. Otherwise the deformities were remarkably symmetrical. This is rather like the type of damage we used to see in thalidomide babies where there was failure of development of the limb buds. I wonder if anyone would like to comment on that?

Professor Polani: I don't think I can make any useful comments. After all, presumably toxic substances whether of biological origin or otherwise will act on the developing embryo or foetus and will affect certain particularly vulnerable stages of development. These stages of development are under genetic control on the one side, but under environmental influence on the other, and you can upset development by upsetting the genetic mechanisms-by point mutation or by chromosomal error-or the environmental mechanisms, or both at the same time. This may lead to certain similarities between environmental damage and genetic damage.

Dr Fraser Roberts: What I could add there, is that 40 years ago my old chief, Professor Crew, used to stress the importance of timing in development. An insult of varied kinds at that precise moment of development will tend to upset particular structures and in particular ways, so the timing in development is all important.

Dr RUBIN: What about microcephaly? It seems to be a feature of some of these cases. It used to be attributed at one time to X-ray therapy, but perhaps this was rather overstated.

Dr Fraser Roberts: Microcephaly certainly can result from treatment with radiation. There was a rather unfortunate phase in the States a good many years ago when a few people induced abortions by massive doses of $\mathrm{X}$-ray and they got a number of microcephalics as a result.

QUESTIONER: I was wondering about the chances of recurrence of a simple thing like spina bifida. Does the extent of the spina bifida alter your advice?

Dr Fraser Roberts: Apparently the extent of the spina bifida does not matter in relation to the risk of recurrence. What does matter very much, and which I did not mention, is if a couple have two children with spina bifida the risk has gone up a lot. It has gone up to one in eight or one in ten. It is not quite independent of severity with hare-lip, but this does not seem to be so with spina bifida.

Dr WooD: I would like to refer to the case of Susan E. Her mother was 41 or 42 years oldo and she had had two normal children, and nowo she has this abnormal child and refuses to have any married life with her husband for fear of a? repetition. I understood you to say there is very little chance of a repetition. Is that so?

Dr Fraser Roberts: Yes, I think that Professor Polani will agree with me that the chance of repetition is negligible.

QUeSTIONER: What advice do you give parents who have had two or, say, three children with gross congenital deformities but all of a different kind?

Dr Fraser RoberTs: I am quite prepared to deal with that one. One does get malformations of entirely different kinds. You can have a couple who have three children all abnormal and all in a different way. Now the tendency, looking at these things, getting a clinical impression, is that there is an undue tendency for certain women or certain couples to have children who are malformed in quite different ways. Now practically never does that stand the test of actual collection of data and when I see couples, as I do quite often as that is why they come up, who have got children who have quite independent anomalies, two or maybe three child 
ren, I harden my heart and say to them that these anomalies are absolutely independent of each other. They have nothing to do with each other whatsoever. You have two or you have three quite independent bits of bad luck. The risk of repetition is the summation of the independent risks of the two and then I often go on to say that a very unlikely event has happened to them. Now, however, unlikely an event, it is going to happen to somebody. The only thing that stuns us is when it happens to us. It is just like winning the football pools in reverse. Somebody has got to win and so I really do harden my heart in those cases and tell them that those anomalies, to the best of our knowledge, are quite independent of each other. You have had two independent bits of bad luck. The chance of repetition of the first is so and so-the chance of repetition of the second is so and so and the chance of either happening again is just the sum of those two.

General Practitioner: Professor Polani, are there any chromosome abnormalities associated with mental abnormality?

Professor Polani: You do not mean mental defect by this, or do you?

General Practitioner: Yes, I do mean mental defect.

Professor Polani: Well, Down's syndrome. or mongolism, of course, and as far as we can tell, Edwards' syndrome and Patau's syndrome. These babies are developmentally and neurologically very abnormal and, in fact, in Patau's syndrome you can see the most striking malformations of the nervous system which also occur to a lesser degree in Edwards' syndrome. Now, in addition you have a certain degree of intellectual abnormality with practically all the other chromosome anomalies involving the sex chromosomes. This is not very severe. Nothing as severe as in mongolism, but, for instance, in Klinefelter's syndrome in males, where you have an XXY sex chromosome complement, you have a certain tendency for intellectual backwardness. This is found in the triple $X$ female, too, though perhaps not so marked as in the Klinefelter's syndrome. There is a tendency for intellectual backwardness even in the XO female with Turner's syndrome. There is a slight lowering of intellectual power in this group of females. Some of them may be brilliant, of course, but as a group these females are somewhat intellectually inferior and also there are other deviations in the way in which their nervous system functions. In addition there is some evidence that in some of these sex chromosome anomalies there is not only a tendency to mental defect, but also to psychotic breakdowns particularly in triple $\mathrm{X}$ females. This is not as firmly based as one would like to have it, but there is some evidence which is reasonable. Even the XXY Klinefelter's are a little odd. They are not just retarded, they are odd.

General Practitioner: But assuming all the physical signs are normal, are there any chromosome abnormalities associated with simple mental defect?

Professor Polani: Well, a triple $\mathbf{X}$ female is normal physically. She does not look any different from another female. She is even fertile. You would not be able to distinguish her really, but her pattern of nervous system functioning is deviant on the whole.

Dr ManN: Are Amsterdam Dwarfs always mentally retarded?

Professor Polani: I am not absolutely sure that this is true of all of them, but it certainly is true of those that have been described. And again, if the neuropathology is any indirect help, and it is obviously of some help, the majority of the autopsied cases show brain abnormality.

General Practitioner: I should like to ask a question about the clinical management of these cases. Amongst those presented tonight there were one or two with correctable anomalies, for instance of the heart. Do the guest speakers nowadays recommend open heart surgery for such children?

Professor Polani: Well, of course, in the case of Edwards' syndrome and Patau's syndrome this practically does not arise. These conditions are fairly rapidly fatal. Most of the children with Edwards' syndrome succumb within the first 4-6 months-practically all I should sayand most children with Patau's syndrome succumb within a year, so I think that their chance of standing major surgery would be very small. They are extremely brittle. They fail to thrive and I don't think they would survive an operation.

The position is different in patients with Down's syndrome. In many centres people do operate if this is what the parents desire and the physicians and surgeons think possible. 
QUESTIONER: Could I ask-is anything known about the inheritance of osteogenesis imperfecta?

Professor Polani: There have been several cases which have been investigated at Guy's and we have found no chromosome abnormalities in them.

Dr. Fraser Roberts: May I, perhaps, just say a quick word about osteogenesis imperfecta. It looks as though it is a thing which is handed on direct from parent to child but, of course, it is a lethal condition if it is severe and a great many of the affected people fail to reproduce. The result is that the proportion of cases due to a very recent mutation are numerous so that a good many cases of osteogenesis are solitary sporadic cases. But where affected people can and do reproduce, then it is transmitted as a dominant trait to half the children of an affected person. It is one of those things which is handed on indefinitely. You may have seen a remarkable, fairly recent, story about porphyria in South Africa where there are estimated to be 8000-10,000 people suffering from South African porphyria and all now are pretty certainly known, thanks to the work of Dr Geoffrey Dean, to be descended from a single couple who married in 1688. There was one mutation, one individual affected originally, and then owing to a population explosion the thing spread like anything and now this original single gene is represented by 8000 or 10,000 . Half the children of affected people are affected and half are normal. When the population is expanding at that sort of rate all the other genes are expanding too.

QUESTIONER: I wonder if I could ask the origin of a trisomy state? Is the fault in one or other germ cell or does it arise later in the fertilized ovum?

Professor Polani: In chromosomal defects we speak very much as one does in the case of single genes, of mutations. We speak of chromosome mutations in this particular instance. These almost invariably, as Dr Fraser Roberts has said, arise de novo for the simple reason that the affected individual is either going to die before he reproduces, or is sterile and does not transmit. This is not absolutely true, but is in general valid. As far as we know, most of these chromosome mutations originate in the germ-cell line, but a number of them arise in the zygote itself after fertilization and lead to mosaicism. We may assume that the majority of the chromosome mutations without mosaicism arise in the germ- cell line. Indirect evidence suggests that, as far as mongolism is concerned, the chromosome mutation most often appears in the maternal germ-cell line. The evidence is that mongolism is correlated with advancing age of the mother, not with advancing age of the father. Probably this is true for some of the other autosomal chromosome mutations we have been discussing, but the evidence in these is not quite as clear-cut as in mongolism because the numbers as yet are rather small. This is also true in the sex chromosome trisomies. In other words there is a maternal age effect, as far as we know, in Klinefelter's syndrome and in triple $X$ females. However, there is no maternal age effect in the production of XO females. Consequently the mechanism of origin of this chromosome mutation presumably is different than in mongolism.

Dr ManN: May I now ask Dr Elliott to express our thanks to Professor Polani and Dr Fraser Roberts.

Dr ElliotT: I have to start off by confessing that I have always been a little dispirited about doing post-mortems on deformed children. I have always thought it was a rather degrading pastime that really would not get one anywhere. But, iro fact, the recent discoveries, which the speakers this evening have described so well, have show us that, far from not getting us anywhere, this is a field in which some of the most fascinating advances in medicine over the last few years have been made. As Professor Polani showed us, there are plenty of autosomes, and it seems likely that there are still quite a number of other deformities which are lurking like outer planets in the solar system, waiting to be discovered; which is a great encouragement to anyone thinking of taking up this work. It gives one an entirely new outlook on deformity and on this hitherto rather sterile aspect of neonatal disease. We are extremely grateful to Professor Polani and Dr Fraser Roberts for the practical and interesting picture which they have given us this evening, and I would like to thank them both very much.

\section{Acknowledgments}

We wish to express our thanks to the Nestlé Co. Ltd, for an annual grant in support of these Conferences.

Fig. 27 is reproduced by kind permission of Dr A. Taylor and the Editors of Developmental Medicine and Child Neurology. Figs. 31 and 32 are reproduced by courtesy of the Editors of Guy's Hospital Reports.

Dr Bruno Gans kindly provided clinical details of Susan C. and her photograph in early infancy (Fig. 14). 